\title{
Adrenalectomy using natural orifice translumenal endoscopic surgery (NOTES): A transvaginal retroperitoneal approach
}

\author{
Silvana Perretta $\cdot$ Pierre Allemann $\cdot$ \\ Mitsuhiro Asakuma · Bernard Dallemagne • \\ Jacques Marescaux
}

Received: 5 September 2008/ Accepted: 12 January 2009/Published online: 5 March 2009

(C) Springer Science+Business Media, LLC 2009

\begin{abstract}
Background Endoscopic adrenalectomy currently is performed using either a retroperitoneal or transperitoneal approach. The retroperitoneal approach is ideal for patients with small lesions who have undergone previous intraabdominal surgery. This study aimed to explore transvaginal retroperitoneal right and left adrenalectomies in porcine and cadaver models.

Methods Right and left adrenalectomies were performed for two female pigs. With the pig supine under general anaesthesia, the retroperitoneal space was entered with a double-channel endoscope (Storz) through a posterior colpotomy. A retroperitoneal tunnel was fashioned using blunt dissection with the assistance of low carbon dioxide insufflation up to the inferior pole of the kidney. Dissection of the upper renal pole allowed access to the adrenal gland. Using blunt dissection, a plane was created between the aorta on the left and the adrenal gland and inferior vena cava on the right. The left main middle vascular pedicle was identified and taken between clips, whereas an endoloop was used on the right side. The specimen was retrieved intact with a polypectomy snare. The same access then was reproduced with two female cadavers.

Results Transvaginal retroperitoneal adrenalectomies were successfully accomplished with a transvaginal
\end{abstract}

Electronic supplementary material The online version of this article (doi:10.1007/s00464-009-0367-9) contains supplementary material, which is available to authorized users.

S. Perretta · P. Allemann - M. Asakuma - B. Dallemagne .

J. Marescaux ( $\square)$

IRCAD/EITS Institute, Strasbourg Cedex, France

e-mail: jacques.marescaux@ircad.fr

P. Allemann

e-mail: pierre.allemann@ircad.u-strasbg.fr approach using natural orifice translumenal endoscopic surgery (NOTES). The operative time was $70 \mathrm{~min}$, and there was no injury to the retroperitoneal structures. The access was effectively reproduced in the cadaver model, with prompt identification of the retroperitoneal anatomic landmarks.

Conclusion Transvaginal retroperitoneal NOTES adrenalectomy is feasible in the porcine model. It reaches the adrenal proper anatomic plane with no need for dissection or retraction of the surrounding organs. This technique might be especially valuable for patients with multiple previous abdominal operations and obese patients in that allows direct access to the adrenal gland and minimizes the cardiovascular and pulmonary risk related to carbon dioxide pneumoperitoneum. Although the operation was successfully validated with cadavers, further experiments and better tools are needed before NOTES transvaginal retroperitoneal access is considered for humans.

Keywords Adrenalectomy · NOTES · Retroperitoneum · Transvaginal 